DOI: https://doi.org/10.24127/ajpm.v9i3.3017

\title{
PENGEMBANGAN VIDEO ANIMASI PEMBELAJARAN BANGUN RUANG SISI DATAR BERORIENTASI PADA KEMAMPUAN SPASIAL
}

\author{
Shelly Lubis ${ }^{1}$, Sri Andayani², Habibullah ${ }^{3}$ \\ ${ }^{1,2,3}$ Pendidikan Matematika, Universitas Negeri Yogyakarta, Yogyakarta, Indonesia

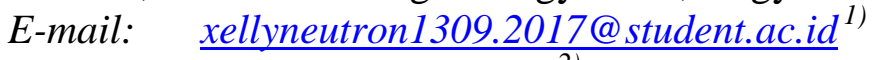 \\ andayani@uny.ac.id $^{2)}$ \\ habibullah_nz@yahoo.co.id ${ }^{3)}$
}

Received 06 August 2020; Received in revised form 09 September 2020; Accepted 26 September 2020

\begin{abstract}
Abstrak
Penelitian ini merupakan penelitian pengembangan yang bertujuan untuk mengembangkan media pembelajaran video animasi yang valid, praktis dan efektif. Subjek penelitian ini adalah 34 orang siswa yang terdiri dari 12 orang siswa laki-laki dan 22 orang siswa perempuan dari salah satu SMP Negeri di Yogyakarta. Teknik pengumpulan data dilakukan dengan angket penilaian kepraktisan media oleh guru dan siswa, serta tes kemampuan spasial yang terdiri dari 12 butir soal pilihan ganda untuk menguji masing-masing komponen kemampuan spasial yaitu spatial visualization, spatial orientation, dan spatial relation. Hasil penelitian menunjukkan bahwa penilaian yang diperoleh dari ahli materi dan ahli media menyatakan media yang dikembangkan memenuhi kriteria valid, sedangkan hasil penilaian yang diberikan oleh guru dan siswa menyatakan media memenuhi kriteria praktis. Media tersebut juga dinyatakan efektif jika ditinjau dari kemampuan spasial karena sebanyak 75,9\% siswa berhasil memperoleh skor ketuntasan. Kemampuan spasial sangat penting dimiliki oleh siswa karena banyak penelitian yang menyatakan bahwa kemampuan spasial berpengaruh terhadap kesuksesan seseorang di bidang Science, Technology, Engineering dan Mathematics (STEM), serta terhadap prestasi matematika siswa.
\end{abstract}

Kata kunci: Kemampuan spasial; media pembelajaran; video animasi.

\begin{abstract}
This research is a development research which aims to develop a valid, practical and effective animated learning video. The subjects involved were 34 students consisting of 12 male and 22 female students from one of the state junior high schools in Yogyakarta. Data collection were carried out with a questionnaire assessment of the practicality of the media by teachers and students, as well as a spatial ability test consisting of 12 multiple choice questions to test each component of spatial ability, namely spatial visualization, spatial orientation, and spatial relations. The results showed that the assessment obtained from material experts and media experts stated that the developed media met valid criteria, while the assessment results given by teachers and students stated that the media met practical criteria. The media was also effective when viewed from spatial ability because $75.9 \%$ of students achieved mastery level scores. Spatial ability is very important for students as reported by many studies stating that spatial ability influences a person's success in the fields of Science, Technology, Engineering and Mathematics (STEM) and related to students' mathematics achievement
\end{abstract}

Keywords: Animated video; learning media; spatial ability.

This is an open access article under the Creative Commons Attribution 4.0 International License

\section{PENDAHULUAN}

Tes kemampuan spasial merupakan salah satu bagian dari rangkaian tes masuk perguruan tinggi maupun tes untuk melamar pekerjaan. Hal tersebut karena kemampuan spasial memiliki hubungan yang positif dengan keberhasilan akademik (Turgut \& 
Yilmaz, 2012). Gilligan, Flouri, dan Farran (2017) menyatakan bahwa kemampuan spasial dapat menjadi prediktor jangka panjang kesuksesan di bidang Science, Technology, Engineering dan Mathematics (STEM). Pernyataan tersebut sejalan dengan pendapat Cole, Cohen, Wilhelm, dan Lindell (2018) bahwa kemampuan spasial berkaitan dengan prestasi siswa di bidang STEM.

Pada pelajaran matematika, kemampuan spasial siswa sangat berpengaruh terhadap keberhasilan mereka pada topik geometri (Farisdianto \& Budiarto, 2014; Hannafin, Truxauw, Vermillion, \& Liu, 2008; Karaman \& Toğrol, 2009). Sementara itu, menurut Kospentaris dan Spyrou (2010) kegiatan pembelajaran geometri ternyata juga berpengaruh terhadap perkembangan kemampuan spasial siswa. Kemampuan ini sulit untuk dikembangkan jika hanya mengandalkan pembelajaran melalui buku (Lin, Chen, \& Lou, 2014).

Lowrie, Logan, dan Ramful (2016) menjelaskan bahwa terdapat hubungan antara penalaran spasial dan prestasi belajar matematika siswa. Secara spesifik Habacha, Molinaro, dan Dosseville (2014) menyatakan bahwa kemampuan spasial laki-laki lebih baik dari perempuan. Hal tersebut dapat dikarenakan perbedaan pengalaman spasial yang dimiliki oleh laki-laki dan perempuan, misalnya pengalaman menggunakan komputer yang ternyata dapat meningkatkan kemampuan spasial (Baenninger \& Newcombe, 1989; Chan, 2007; De Lisi \& Cammarano, 1996; Terlecki \& Newcombe, 2005).

Meskipun kemampuan spasial penting untuk dimiliki oleh siswa, namun pada kenyataannya kemampuan spasial siswa masih tergolong rendah (Güven \& Kosa, 2008; Sumarni \&
Prayitno, 2016; Turgut \& Yilmaz, 2012). Hal tersebut disebabkan karena kemampuan spasial siswa belum terlatih (Indriani, 2018). Kemampuan spasial yang rendah, berakibat pada rendahnya daya serap Ujian Nasional (UN) matematika untuk topik geometri. Pada jenjang SMP, daya serap UN topik geometri untuk tingkat nasional selama tiga tahun berturut-turut masih rendah, yaitu pada tahun 2015 hanya mecapai rata-rata 52,04 (BNSP, 2015), pada tahun 2016 turun menjadi 47,19 (BNSP, 2016), dan pada tahun 2017 hanya mencapai 48,57 (BNSP, 2017).

Pembelajaran dengan bantuan media yang tepat berpengaruh terhadap peningkatan kemampuan spasial siswa (Uygan \& Kurtuluş, 2016). Menurut Prakoso, Putra, Mentari, dan Rahman (2015) dengan bantuan media pembelajaran, kemampuan spasial siswa dapat dikembangkan. Sedangkan Marunic dan Glazar (2013) dan Onyancha, Derov, dan Kinsey (2009) mengatakan bahwa melalui media pembelajaran, kemampuan spasial siswa dapat dilatih, sehingga kemampuan spasial siswa dapat meningkat. Penggunaan media pembelajaran juga dapat mengurangi kesenjangan antara kemampuan spasial laki-laki dan perempuan (Habacha et al., 2014; Lin et al., 2014). Untuk materi geometri, salah satu media yang dapat menampilkan visualisasi dari objek geometri adalah video animasi. Video pembelajaran juga dapat membantu meningkatkan pemahaman konsep siswa (Hadi, 2017).

Beberapa penelitian telah dilakukan untuk mengembangkan media pembelajaran yang berorientasi pada kemampuan spasial. Misalnya media yang dikembangkan oleh Nasution, Anwar, Sudirman, dan Susiswo (2016) untuk tingkat SMA. Sedangkan untuk jenjang SMP, Lestari (2018) 
mengembangkan suatu media pembelajaran menggunakan aplikasi GeoGebra, namun objek-objek geometri yang ditampilkan masih perlu dikembangkan kompleksitasnya yang disesuaikan dengan indikator kemampuan spasial. Begitu juga dengan perangkat pembelajaran berupa Rencana Pelaksanaan Pembelajaran (RPP) dan Lembar Kerja Siswa (LKS) yang dikembangkan oleh Lusyana (2017) masih perlu dilakukan pengembangan lebih lanjut berupa visualisasi objek geometri dalam bentuk animasi.

Kemampuan spasial didefinisikan sebagai kemampuan untuk memahami hubungan spasial atau keterkaitan di antara objek-objek, mampu mempersepsikan gambar visual dengan tepat, dan menggunakan informasi visual untuk menyusun representasi mental (Khine, 2017). Pemikiran spasial adalah bagian yang terlibat dalam kegiatan seseorang dalam menyelesaikan masalah matematika dengan cara menemukan sudut pandang lain atau penggunaan bantuan gambar tambahan (Turgut \& Uygan, 2015). Keterampilan berpikir spasial merupakan kemampuan untuk menggunakan sifat-sifat spasial dari suatu objek untuk membangun representasi mental (Cole et al., 2018).

Kemampuan spasial terdiri dari beberapa komponen, yaitu spatial visualization yang merupakan kemampuan untuk mengenali objekobjek dua atau tiga dimensi yang telah dimanipulasi (diubah bentuk atau susunan) atau dipindahkan (Uygan \& Kurtuluş, 2016), spatial orientation yang merupakan kemampuan untuk menentukan posisi atau bentuk dari suatu objek jika dilihat dari posisi yang berbeda dengan pengamat lainnya (Ramful, Lowrie, \& Logan, 2017), dan spatial relation yang merupakan kemampuan untuk mengimajinasikan atau memvisualisasikan di dalam pikiran bentuk-bentuk rotasi dari objekobjek dua atau tiga dimensi yang dilihat dari berbagai sudut pandang (Olkun, 2003).

Penelitian ini bertujuan untuk menghasilkan produk pengembangan berupa video animasi pembelajaran untuk materi bangun ruang sisi datar yang dirancang untuk melatih kemampuan spasial siswa. Topik tersebut dipelajari oleh siswa kelas VII pada semester genap.

\section{METODE PENELITIAN}

Penelitian ini dilaksanakan di SMP Negeri 1 Yogyakarta dengan waktu proses pengumpulan data dilakukan pada bulan April hingga Mei 2019. Subyek penelitian adalah 34 orang siswa kelas VIII yang terdiri dari 12 orang siswa laki-laki dan 22 orang siswa perempuan.

Penelitian ini merupakan penelitian pengembangan dengan menerapkan model pengembangan ADDIE yang meliputi tahapan Analyze, Design, Develop, Implement, dan Evaluate (Branch, 2009).

Pada tahap analysis, dilakukan analisis kebutuhan dengan cara melakukan observasi dan wawancara terhadap guru dan siswa di sekolah tempat penelitian untuk memperoleh informasi terkait fasilitas, sarana atau prasarana yang ada di sekolah. Kemudian dilakukan analisis kurikulum untuk mendapatkan informasi terkait topik yang sesuai dengan media yang akan dikembangkan serta kurikulum yang berlaku di sekolah tempat penelitian dan jenis pendekatan atau model pembelajaran yang cocok dengan topik tersebut. Hasil dari analisis kebutuhan dan analisis kurikulum diperoleh gambaran secara umum 
DOI: https://doi.org/10.24127/ajpm.v9i3.3017

kebutuhan-kebutuhan yang akan difasilitasi oleh media yang dikembangkan. Selanjutnya dilakukan analisis karakteristik siswa untuk memperoleh informasi tentang gambaran secara umum karakteristik siswa pada jenjang SMP.

Pada tahap design, dilakukan rancangan terhadap video yang akan dikembangkan berdasarkan hasil pada tahap analyse. Pada tahap ini juga dilakukan perancangan terhadap instrumen tes kemampuan spasial beserta angket penilaian kepraktisan oleh guru dan siswa serta lembar penilaian validitas media oleh ahli materi dan ahli media.

Tahap selanjutnya yaitu tahap development. Pada tahap ini dilakukan pengembangan terhadap produk dan instrumen serta lembar penilaian berdasarkan hasil rancangan pada tahap sebelumnya. Video animasi yang dikembangkan menggunakan bantuan aplikasi GeoGebra dan direkam dengan aplikasi Bandicam. Setelah produk selesai dikembangkan, dilanjutkan ke tahap implementation, yaitu melakukan ujicoba produk. Produk berupa video animasi dan lembar penilaian yang divalidasi oleh ahli materi dan ahli media. Lembar penilaian oleh kedua ahli terdiri dari beberapa butir pernyataan dengan menggunakan skala lima. Setelah produk dinyatakan valid dan direvisi berdasarkan saran, masukan dan komentar ahli, dilakukan ujicoba perorangan untuk melihat keterbacaan atau mengetahui kesalahan-kesalahan kecil yang mungkin terlewati pada saat proses validasi oleh ahli. Ujicoba perorangan dilakukan terhadap 5 orang siswa kelas VIII yang terdiri dari 1 orang siswa laki-laki dan 4 orang siswa perempuan.

Tahap selajutnya yaitu dilakukan ujicoba lapangan (Implement). Pada tahap ini, yang dilakukan adalah ujicoba dalam kegiatan pembelajaran di kelas menggunakan bantuan video pembelajaran pada materi bangun ruang sisi datar sebanyak 4 kali pertemuan. Ujicoba dilakukan terhadap 29 orang siswa yang terdiri dari 11 orang siswa laki-laki dan 18 orang siswa perempuan. Pada pertemuan ke 5 dilaksanakan tes kemampuan spasial yang terdiri dari 12 butir soal pilihan ganda yang terdiri dari 4 butir soal untuk menguji masingmasing komponen kemampuan spasial yaitu spatial visualization, spatial orientation, dan spatial relation. Selain itu, pengumpulan data juga dilakukan dengan angket penilaian kepraktisan media oleh guru dan siswa. Angket penilaian kepraktisan terdiri dari beberapa butir pertanyaan yang menggunakan skala Likert. Data kuantitatif dari hasil penilaian validitas dan kepraktisan kemudian dianalisis dan dikonversi menjadi data kualitatif dengan menggunakan tabel konversi yang dikembangkan oleh Widoyoko (2009) dan dapat dilihat pada Tabel 1.

Tabel 1. Konversi jenis data kuantitatif ke kualitatif.

\begin{tabular}{cc}
\hline Interval & Kategori \\
\hline$X>\bar{x}_{t}+1,8 s b_{t}$ & Sangat baik \\
$\bar{x}_{t}+0,6 s b_{t}<X \leq \bar{x}_{t}+1,8 s b_{t}$ & Baik \\
$\bar{x}_{t}-0,6 s b_{t}<X \leq \bar{x}_{t}+0,6 s b_{t}$ & Cukup baik \\
$\bar{x}_{t}-1,8 s b_{t}<X \leq \bar{x}_{t}-0,6 s b_{t}$ & Kurang baik \\
$X \leq \bar{x}_{t}-1,8 s b_{t}$ & Sangat kurang baik \\
\hline
\end{tabular}


DOI: https://doi.org/10.24127/ajpm.v9i3.3017

Keterangan:

$X=$ skor empiris

$\bar{x}_{t}=$ skor ideal $=\frac{1}{2}($ skor maksimum ideal + skor minimum ideal)

$s b_{t}=$ simpangan baku ideal $=\frac{1}{6}$ (skor maksimum ideal - skor minimum ideal)

Skor maksimum ideal $=$ banyak butir $\times$ skor tertinggi

Skor minimum ideal $=$ banyak butir $\times$ skor terendah

Penilaian kriteria keefektifan produk ditentukan oleh persentase ketuntasan siswa. Kriteria ketuntasan minimal (KKM) pelajaran matematika di sekolah tempat penelitian adalah 75 . Dengan demikian produk yang dikembangkan akan memenuhi kriteria keefektifan jika sebanyak $75 \%$ siswa memperoleh skor yang mencapai KKM.

Setelah tahap implementation selesai dilakukan dan diperoleh hasil dari data yang dianalisis, dilakukan perbaikan produk berdasarkan komentar, masukan dan saran dari siswa dan guru pada lembar penilaian. Perbaikan juga dilakukan berdasarkan hasil observasi pada saat produk diujicobakan dalam kegiatan pembelajaran di kelas.

\section{HASIL DAN PEMBAHASAN}

Setelah melalui tahap analysis, design, dan development, dihasilkan produk pengembangan berupa videovideo animasi pembelajaran untuk materi bangun ruang sisi datar yang dikembangkan berdasarkan indikator yang sesuai dengan definisi dari tiga komponen kemampuan spasial. Cuplikan dari beberapa video yang mewakili indikator kemampuan spasial dapat dilihat pada Gambar 1, Gambar 2 dan Gambar 3.

Gambar 1 menunjukkan cuplikan video animasi jaring-jaring kubus yang memiliki sisi-sisi dengan motif berbeda. Motif atau pola tersebut tergambar di sisi luar dan dalam kubus. Dengan demikian siswa dapat melihat kubus dan jaring-jaring tersebut dari arah atau sudut pandang yang berbeda. Tujuannya yaitu untuk melatih kemampuan spatial visualization dan spatial relation siswa. Dengan demikian siswa dapat melihat hubungan antara sisi-sisi kubus yang memiliki perbedaan pola tersebut baik yang tergambar di luar maupun di dalam kubus. Setelah mengamati animasi tersebut siswa diminta untuk menentukan sisi-sisi mana saja yang berhadapan.

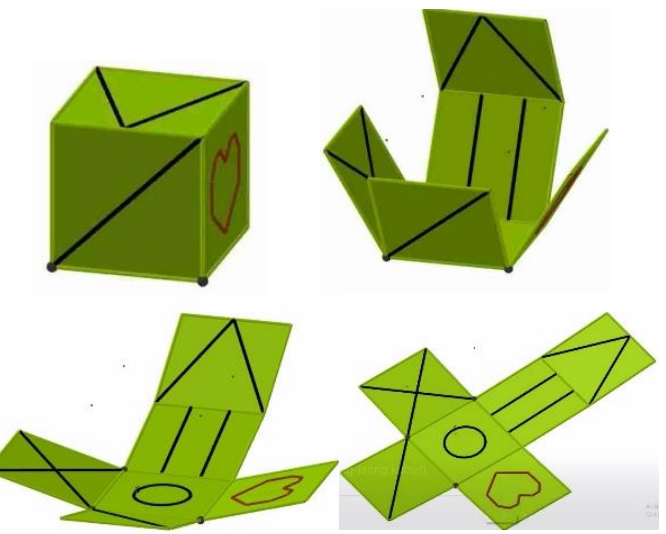

Gambar 1. Tangkapan gambar animasi jaring-jaring kubus.
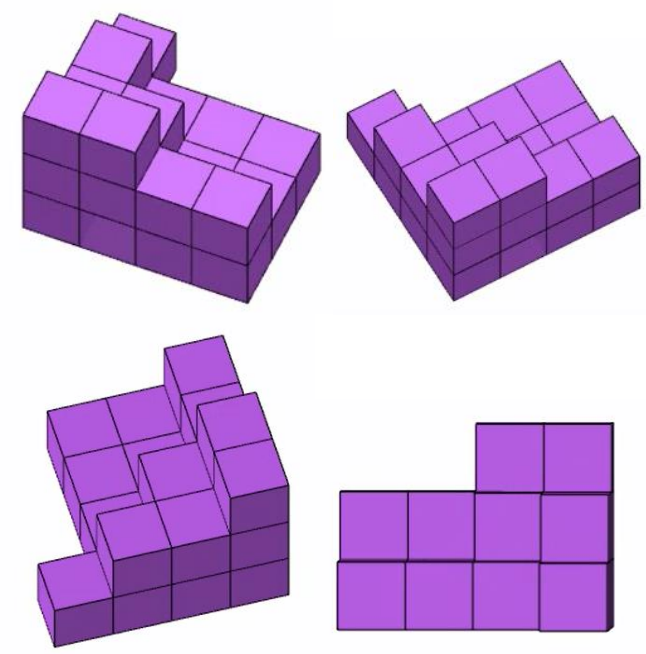

Gambar 2. Tangkapan gambar animasi bangun ruang tak beraturan. 
Gambar 2 menunjukkan cuplikan animasi objek bangun ruang tak beraturan yang dibentuk dari tumpukan beberapa kubus satuan. Dalam video tersebut ditampilkan rotasi dari objek yang dirancang agar siswa dapat mengamati bentuk ojek jika dilihat dari arah yang berbeda (dari atas atau dari samping). Tujuannya yaitu untuk melatih kemampuan spatial orientation dan spatial relation. Setelah mengamati animasi tersebut, siswa diminta untuk menentukan berapa banyak kubus satuan yang harus ditambah agar objek tersebut dapat membentuk suatu kubus dengan panjang rusuk 4 satuan yang juga dapat membantu siswa memahami konsep volume kubus.

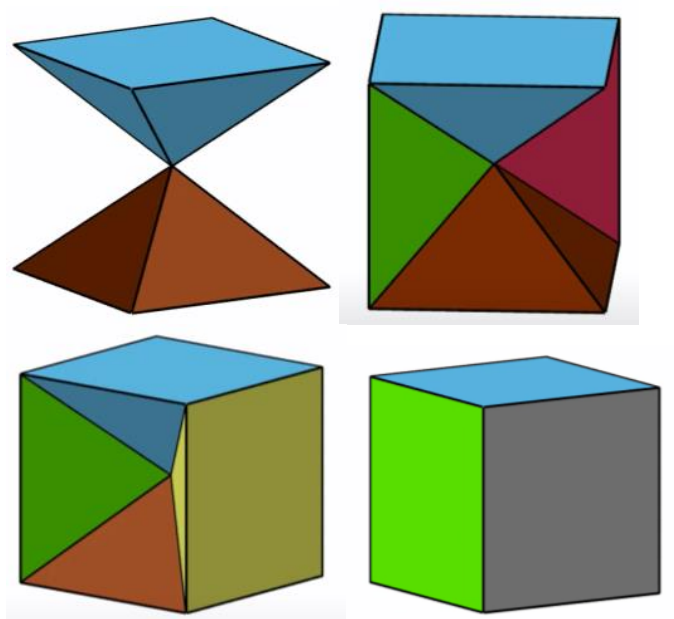

Gambar 3. Tangkapan gambar animasi volume limas.

Gambar 3 merupakan cuplikan video animasi yang menampilkan suatu kubus yang terbentuk dari enam limas yang kongruen yang akan membimbing siswa menemukan rumus volume limas. Penggunaan warna yang berbeda pada masing-masing limas dirancang agar siswa dapat melihat hubungan antara posisi dari setiap limas dengan limas lainnya sehingga kemampuan spatial visualization mereka dapat terlatih. Objek tersebut juga diputar agar siswa dapat melihat dari arah yang berbeda sehingga dapat melatih kemampuan spatial relation siswa.

Berdasarkan hasil penilaian dari ahli media dan ahli materi, video animasi yang dikembangkan memenuhi kategori valid dan siap untuk diujicobakan dalam kegiatan pembelajaran di kelas. Setelah 4 kali pertemuan pada materi bangun ruang sisi datar, siswa kemudian diberikan tes kemampuan spasial. Selain itu siswa dan guru juga diberikan lembar penilaian kepraktisan media. Hasil penilaian dari guru dan siswa diperoleh kesimpulan bahwa video animasi yang dikembangkan praktis untuk digunakan dalam kegiatan pembelajaran di kelas. Sedangkan dari hasil tes kemampuan spasial (Tabel 2), sebanyak 75,9\% siswa mencapai skor ketuntasan dengan skor tertinggi adalah 100 dan skor terendah adalah 41,7, sedangkan rata-rata keseluruhan adalah 76,7.

Dengan demikian dapat disimpulkan bahwa video yang dikembangkan memenuhi kriteria efektif jika ditinjau dari kemampuan spasial. Kesimpulan tersebut sesuai dengan laporan penelitian yang menyebutkan bahwa kemampuan spasial dapat dikembangkan melalui latihan (Marunic \& Glazar, 2013; Onyancha et al., 2009).

Tabel 2. Rincian analisis skor tes kemampuan spasial.

\begin{tabular}{ccclc}
\hline No & Keterangan & Nilai & \multicolumn{1}{c}{ Keterangan } & Persentase \\
\hline 1 & Skor tertinggi & 100 & Tuntas KKM & 22 \\
2 & Skor terendah & 41,7 & Tidak tuntas KKM & 7 \\
3 & Rata-rata & 76,7 & Persentase banyak siswa yang tuntas & 75,9 \\
\hline
\end{tabular}


DOI: https://doi.org/10.24127/ajpm.v9i3.3017

Jika dianalisis berdasarkan masing-masing komponen kemampuan spasial, terdapat satu komponen yang belum mencapai kriteria ketuntasan. Dari Tabel 3 terlihat bahwa untuk komponen kemampuan spatial orientation belum dicapai kriteria ketuntasan. Hal tersebut dikarenakan hanya sebanyak $72,4 \%$ siswa yang mencapai ketuntasan pada kategori ini. Sedangkan untuk dua komponen lainnya yaitu kemampuan spatial visualization dan spatial relation dicapai kriteria ketuntasan yaitu masing-masing sebesar $79,3 \%$ dan 93,1\% yang menunjukkan bahwa kemampuan siswa pada dua komponen ini telah berkembang dan termasuk dalam kategori baik.
Berdasarkan hasil analisis tersebut maka perlu dikembangkan produk tambahan yang dirancang dengan memfokuskan pada kemampuan spatial orientation siswa.

Tabel 3. Rincian analisis skor per komponen kemampuan spasial.

\begin{tabular}{cc}
\hline $\begin{array}{c}\text { Komponen } \\
\text { kemampuan spasial }\end{array}$ & $\begin{array}{c}\text { \% banyak siswa } \\
\text { yang tuntas }\end{array}$ \\
\hline Spatial orientation & 72,4 \\
Spatial visualization & 79,3 \\
Spatial relation & 93,1 \\
\hline
\end{tabular}

Jika dilakukan analisis lebih dalam terhadap skor ketuntasan siswa laki-laki dan siswa perempuan, terdapat perbedaan seperti yang dapat dilihat pada Tabel 4.

Tabel 4. Analisis skor ketuntasan siswa laki-laki dan perempuan.

\begin{tabular}{ccc}
\hline \multirow{2}{*}{ Komponen } & \multicolumn{2}{c}{$\%$ banyak siswa yang tuntas } \\
\cline { 2 - 3 } & Laki-laki & Perempuan \\
\hline Spatial orientation & 100 & 55,6 \\
Spatial visualization & 100 & 66,7 \\
Spatial relation & 100 & 88,9 \\
Kemampuan spasial secara keseluruhan & 100 & 70,4 \\
\hline
\end{tabular}

Dari Tabel 4 terlihat bahwa semua siswa laki-laki berhasil mencapai kriteria ketuntasan untuk semua komponen kemampuan spasial. Sedangkan siswa perempuan hanya sebanyak $55,6 \%$ yang mencapai ketuntasan pada komponen kemampuan spatial orientation, sebanyak $66,7 \%$ pada komponen kemampuan spatial visualization, dan sebanyak $88,9 \%$ pada kemampuan spatial relation. Secara keseluruhan hanya $61,1 \%$ siswa perempuan yang memperoleh skor ketuntasan.

Hasil dari penelitian ini dipengaruhi oleh beberapa faktor. Salah satu faktor yang mempengaruhi adalah tidak tercapainya target jumlah tatap muka yang direncanakan. Pada tahap awal perencanaan ujicoba lapangan, video-video hasil pengembangan akan diujicobakan di dalam kegiatan belajar mengajar di kelas untuk materi Bangun Ruang Sisi Datar selama 8 kali pertemuan tatap muka. Namun, karena ada beberapa kegiatan persiapan ujian nasional yang diadakan di sekolah, sehingga menyebabkan siswa kelas 7 dan kelas 8 harus diliburkan. Hal tersebut berakibat pada berkurangnya jumlah pertemuan tatap muka untuk pelajaran matematika, sehingga untuk materi bangun ruang sisi datar dipangkas menjadi 4 kali pertemuan. Hal tersebut berdampak pada kurangnya 
DOI: https://doi.org/10.24127/ajpm.v9i3.3017

frekuensi latihan siswa pada penggunaan media yang dikembangkan. Faktor berikutnya yang mempengaruhi hasil penelitian ini yaitu pada fasilitas yang digunakan oleh siswa. Pada tahap awal perencanaan ujicoba lapangan, kegiatan pembelajaran dengan bantuan media video animasi yang dikembangkan seharusnya dilaksanakan di laboratorium komputer. Hal tersebut bertujuan agar masing-masing siswa dapat lebih fokus dalam mengamati objek-objek pada video yang disajikan jika satu siswa menggunakan 1 komputer. Namun dikarenakan terdapat kendala saat ujicoba lapangan, sehingga menyebabkan kegiatan pembelajaran tidak dapat dilakukan di laboratorium komputer. Kegiatan pembelajaran kemudian tetap dilakukan di kelas dengan menggunakan bantuan laptop. Siswa dibagi menjadi beberapa kelompok yang terdiri dari 3 atau 4 orang dan masing-masing kelompok difasilitasi dengan satu unit laptop. Hal tersebut berdampak pada berkurangnya fokus siswa dalam mengamati video tersebut jika dibandingkan dengan penggunaan komputer untuk masingmasing siswa.

Kelebihan dari video hasil pengembangan ini terletak pada karakteristik yang dirancang dan disesuaikan dengan indikator ketiga komponen kemampuan spasial, sehingga secara spesifik dapat melatih kemampuan tersebut. Sedangkan kekurangannya yaitu terletak pada terbatasnya aplikasi yang dapat digunakan oleh penulis dalam mengembangakan video yang lebih variatif.

Untuk perbedaan hasil tes kemampuan spasial siswa laki-laki dan perempuan, hal ini sesuai dengan laporan banyak penelitian yang menyebutkan bahwa kemampuan spasial laki-laki lebih baik dari perempuan (Chan, 2007; Colom, Contreras, Arend, Leal, \& Santacreu, 2004; Geary, Saults, Liu, \& Hoard, 2000; Habacha et al., 2014; Levine, Vasilyeva, Lourenco, Newcombe, \& Huttenlocher, 2005; Li \& O'Boyle, 2008; Lin et al., 2014; Maeda \& Yoon, 2013; Németh \& Hoffmann, 2006). Namun dengan latihan yang rutin, perbedaan tersebut akan dapat dikurangi.

\section{KESIMPULAN DAN SARAN}

Hasil penilaian yang diperoleh dari ahli materi dan ahli media menunjukkan bahwa video yang dikembangkan memenuhi kriteria valid, sedangkan hasil penilaian yang diberikan oleh guru dan siswa menunjukkan bahwa video tersebut memenuhi kriteria praktis. Hasil tes kemampuan spasial menunjukkan bahwa video tersebut efektif untuk melatih kemampuan spasial siswa karena sebanyak $75,9 \%$ siswa berhasil memperoleh skor ketuntasan.

Dalam penelitian ini, produk diujicobakan terhadap sampel yang merupakan sekelompok siswa dalam 1 kelas. Oleh karena itu, penulis menyarankan untuk dilakukan penelitian lebih lanjut dengan melakukan ujicoba produk terhadap kelas pembanding (penelitian eksperimen) untuk mengetahui tingkat efektifitas produk yang telah dikembangkan.

Hasil dari produk pengembangan media pembelajaran berupa video animasi diharapkan akan memberikan manfaat bagi siswa dalam melatih kemampuan spasial mereka pada proses kegiatan baik di dalam maupun di luar kelas. 
DOI: https://doi.org/10.24127/ajpm.v9i3.3017

\section{DAFTAR PUSTAKA}

Baenninger, M., \& Newcombe, N. (1989). The role of experience in spatial test performance: A metaanalysis. Sex Roles, 20(5-6), 327344.

https://doi.org/10.1007/BF0028772 9

BNSP. (2015). Laporan hasil ujian nasional tahun pelajaran 2014/2015.

BNSP. (2016). Laporan hasil ujian nasional tahun pelajaran 2015/2016.

BNSP. (2017). Laporan hasil ujian nasional tahun pelajaran 2016/2017.

Branch, R. M. (2009). Instructional design: The ADDIE approach. New York: Springer.

Chan, D. W. (2007). Gender differences in spatial ability: relationship to spatial experience among Chinese gifted students in Hong Kong. Roeper Review, 29(4), 277-282.

Cole, M., Cohen, C., Wilhelm, J., \& Lindell, R. (2018). Spatial thinking in astronomy education research. Physical Review Physics Education Research, 14(1), 1-27. https://doi.org/10.1103/PhysRevPh ysEducRes.14.010139

Colom, R., Contreras, M. J., Arend, I., Leal, O. G., \& Santacreu, J. (2004). Sex differences in verbal reasoning are mediated by sex differences in spatial ability. The Psychological Record, 54(3), 365372.

De Lisi, R., \& Cammarano, D. M. (1996). Computer experience and gender differences in undergraduate mental rotation performance. Computers in Human Behavior, 12(3), 351-361. https://doi.org/10.1016/07475632(96)00013-1
Farisdianto, D. D., \& Budiarto, M. T. (2014). Profil kemampuan spasial siswa SMP dalam menyelesaikan masalah Geometri ditinjau dari perbedaan kemampuan Matematika. Jurnal Ilmiah Pendidikan Matematika, 3(3), 7784.

Geary, D. C., Saults, S. J., Liu, F., \& Hoard, M. K. (2000). Sex differences in spatial cognition, computational fluency, and arithmetical reasoning. Journal of Experimental Child Psychology, 77(4), 337-353. https://doi.org/10.1006/jecp.2000.2 594

Gilligan, K. A., Flouri, E., \& Farran, E. K. (2017). The contribution of spatial ability to mathematics achievement in middle childhood. Journal of Experimental Child Psychology, 163, 107-125. https://doi.org/10.1016/j.jecp.2017. 04.016

Güven, B., \& Kosa, T. (2008). The effect of dynamic geometry software on student mathematics teachers' spatial visualization skills. Turkish Online Journal of Educational Technology, 7(4), 100-107.

Habacha, H., Molinaro, C., \& Dosseville, F. (2014). Effects of gender, imagery ability, and sports practice on the performance of a mental rotation tasks. American Journal of Psychology, 127(3), 313-323.

Hadi, S. (2017). Efektifitas penggunaan video sebagai media pembelajaran untuk siswa sekolah dasar. In Prosiding TEP \& PDs (pp. 96102).

Hannafin, R. D., Truxauw, M. P., Vermillion, J. R., \& Liu, Y. (2008). Effects of spatial ability 
DOI: https://doi.org/10.24127/ajpm.v9i3.3017

and instructional program on Geometry achievement. The Journal of Educational Research, 101(3), 148-156.

Indriani, K. W. A. (2018). Analisis kemampuan spasial siswa kelas VII SMPN 1 Maluk melalui aktifitas Cut Folding Paper pada pembelajaran berkerangka kerja Elpsa. In Prosiding Seminar Nasional Pendidik dan Pengembang Pendidikan Indonesia (pp. 446-452).

Karaman, T., \& Toğrol, A. Y. (2009). Relationship between gender, spatial visualization, spatial orientation, flexibility of closure abilities and performance related to plane geometry subject among sixth grade students. Boğaziçi University Journal of Education, 26(1), 1-25.

Khine, M. S. (2017). Spatial Cognition: Key to STEM Success. In M. S. Khine (Ed.), Visual-spatial Ability in STEM Education: Transforming Research into Practice. Perth: Springer.

Kospentaris, G., \& Spyrou, P. (2010). The effects of high school geometry instruction on the performance in spatial tasks. Journal for Geometry and Graphics, 14(2), 227-244.

Lestari, T. K. (2018). Pengembangan perangkat pembelajaran geometri SMP berbasis Computer assisted instruction (CAI) dan berorientasi pada prestasi belajar, kemampuan keruangan, dan kemandirian belajar matematika. Universitas Negeri Yogyakarta, Yogyakarta.

Levine, S. C., Vasilyeva, M., Lourenco, S. F., Newcombe, N. S., \& Huttenlocher, J. (2005). Socioeconomic status modifies the sex difference in spatial skill.
Psychological Science, 16(11), 841-845.

https://doi.org/10.1111/j.1467-

9280.2005.01623.x

Li, Y., \& O'Boyle, M. W. (2008). How sex, native language, and college major relate to the cognitive strategies used during 3-D mental rotation. The Psychological Record, 58, 287-300.

Lin, C.-H., Chen, C.-M., \& Lou, Y.-C. (2014). Developing spatial orientation and spatial memory with a Treasure Hunting Game. Educational Technology \& Society, 17(3), 79-92. Retrieved from https://www.jstor.org/stable/pdf/je ductechsoci.17.3.79.pdf

Lowrie, T., Logan, T., \& Ramful, A. (2016). Spatial reasoning influences students' performance on mathematics tasks. In Proceedings of the 39th annual conference of the Mathematics Education Research Group of Australasia (pp. 407-414). Adelaide. Retrieved from https://eric.ed.gov/?id=ED572328

Lusyana, E. (2017). Pengembangan perangkat pembelajaran matematika SMK menggunakan teori Van Hiele berorientasi pada penalaran spasial, prestasi dan minat belajar matematika. Universitas Negeri Yogyakarta, Yogyakarta.

Maeda, Y., \& Yoon, S. Y. (2013). A meta-analysis on gender differences in mental rotation ability measured by the Purdue spatial visualization tests: visualization of rotations (PSVT:R). Educational Psychology Review, 25(1), 69-94. https://doi.org/10.1007/s

Marunic, G., \& Glazar, V. (2013). Spatial ability through engineering 
DOI: https://doi.org/10.24127/ajpm.v9i3.3017

graphics education. International Journal of Technology and Design Education, 23(3), 703-715. https://doi.org/10.1007/s10798-

012-9211-y

Nasution, S. H., Anwar, L., Sudirman, \& Susiswo. (2016). Pengembangan media pembelajaran untuk mendukung kemampuan penalaran spasial siswa pada topik dimensi tiga kelas $\mathrm{X}$. Jurnal KIP, 4(2), 903-913.

Németh, B., \& Hoffmann, M. (2006). Gender differences in spatial visualization among engineering students. Annales Mathematicae et Informaticae, 33, 169-174.

Olkun, S. (2003). Making Connections : Improving Spatial Abilities with Engineering Drawing Activities. International Journal of Mathematics Teaching and Learning, 3(1), 1-10.

Onyancha, R. M., Derov, M., \& Kinsey, B. L. (2009). Improvement in spatial ability as a result of targeted training and computer-aided design software use: analysis of object geometries and rotation types. Journal of Engineering Education, 98(2), 157-167.

Prakoso, W. D., Putra, M. Y. D., Mentari, A., \& Rahman, B. (2015). Peningkatan kemampuan spasial matematis melalui pembelajaran geometri berbantuan Geogebra. Seminar Nasional Matematika Dan Pendidikan Matematika Uny 2015, 497-504.

Ramful, A., Lowrie, T., \& Logan, T. (2017). Measurement of spatial ability: construction and validation of the spatial reasoning instrument for middle school students. Journal of Psychoeducational Assessment, 35(7), 709-727. https://doi.org/10.1177/073428291
6659207

Sumarni, \& Prayitno, A. T. (2016). Kemampuan visual-spatial thinking dalam geometri ruang mahasiswa Universitas Kuningan. Jurnal Edukasi Dan Sains Matematika, 2(2), 81-99.

Terlecki, M. S., \& Newcombe, N. S. (2005). How important is the digital divide? The relation of computer and videogame usage to gender differences in mental rotation ability. Sex Roles, 53(5/6), 433-441.

https://doi.org/10.1007/s11199005-6765-0

Turgut, M., \& Uygan, C. (2015). Designing spatial visualization tasks for middle school students with 3D modelling software: An instrumental approach. International Journal for Technology in Mathematics Education, 22(2), 45-51.

Turgut, M., \& Yilmaz, S. (2012). Relationships among preservice primary mathematics teachers' gender, academic success and spatial ability. International Journal of Instruction, 5(2), 5-20.

Uygan, C., \& Kurtuluş, A. (2016). Effects of teaching activities via Google Sketchup and concrete models on spatial skills of preservice mathematics teachers. Turkish Journal of Computer and Mathematics Education (TURCOMAT), 7(3), 510-510. https://doi.org/10.16949/turkbilmat .273993

Widoyoko, S. E. P. (2009). Evaluasi program pembelajaran panduan praktis bagi pendidik dan calon pendidik. Yogyakarta: Pustaka Belajar. 